\title{
Examining the Career Pathways of Educators with Superintendent Certification ${ }^{1}$
}

\author{
Bradley W. Davis \\ The University of Texas at Arlington \\ b_w_davis@utexas.edu
}

\author{
Alex J. Bowers \\ Teachers College, Columbia University \\ Bowers@tc.edu
}

\begin{abstract}
:
Purpose: We used gatekeeping theory to frame our examination of whether and when educators with superintendent certification become superintendents, and how their likelihood of making that transition is influenced by race, sex, and other characteristics. Further, we sought to identify variation in career pathways to the superintendency.

Data and Method: We analyzed 26,071 observations of 4,813 unique individuals, representing the entire population of Texas public school educators who obtained their first superintendent certificate between the 2000-01 and 2014-15 school years. We constructed alluvial diagrams to visualize these educators' career pathways. In addition to compiling a life table and visual displays of hazard, we utilized a discrete-time hazard model to control for individual and contextual characteristics associated with transitions into the superintendency.

Findings: Educators are most likely to enter the superintendency in the academic year immediately following that in which they obtained the requisite certification. Further, pathways to the superintendency differ greatly based on educator sex and race, as well as the level and locale employment setting. Finally, we determined that age, experience, education, level of employment, and sex all have statistically significant impacts on the likelihood of becoming a superintendent.
\end{abstract}

Implications for Research and Practice: We discuss the role that researchers must play in coordinating with practitioners to ensure more equitable opportunity for aspiring superintendents. We also emphasize the important role that preparation programs play in preparing candidates for the job market. Finally, we ponder further expansions of similar pre-superintendency research, as well as more robust applications of alluvial diagrams.

KEYWORDS: superintendents, intersectionality, alluvial, career pathways, certification, gatekeeping, school district leadership

\footnotetext{
${ }^{1}$ This document is a pre-print of this manuscript, published in the journal Educational Administration Quarterly. Citation: Davis, B., Bowers, A.J. (2019) Examining the Career Pathways of Educators with Superintendent Certification. Educational Administration Quarterly, 55(1), 3-41. https://doi.org/10.1177/0013161X18785872
}

Little is known about the early stages of career pathways into educational administration (Davis, Gooden, \& Bowers, 2017), and what is known is almost exclusive to campus-level leaders. Amongst the studies that investigate the career experiences of district-level leaders (e.g. Petersen, Fusarelli, \& Kowalski, 2008; Roberts, Hanna, \& Womack, 2012; Smith, 2008), most focus on the novice superintendent, investigating their experiences after obtaining the position. Much like the research on building-level leadership career pathways (Davis et al., 2017), those that focus on latter portions of superintendent careers, tend to focus on turnover and its causes (e.g. Alsbury, 2003, 2008; Grissom \& Andersen, 2012; Grissom \& Mitani, 2016; Natkin, Cooper, Alborano, Padilla, \& Ghosh, 2003). Superintendent turnover is certainly an important issue, as reported in the research literature and the media (Melia, 2016; Orr, 2006), as its frequent occurrence can negatively impact day-to-day management and broader reform efforts (Alsbury, 2008; Natkin et al., 2003; SERVE, 1994), both of which have implications for student achievement. However, in comparison to this relatively sparse yet important literature on superintendent turnover, almost nothing is known about the career pathways into the superintendency, such as how personnel who eventually become superintendents receive certification for district-level administration, and their experiences from certification to the superintendency.

While much of the research, to date, on the career pathways of aspiring superintendents from formal preparation to superintendency, focuses on the curriculum and experiences provided through certification programs (Davis et al., 2017; Orr, 2006), it also highlights the timing of certification in comparison to when the superintendency role is secured (Cooper, Fusarelli, Jackson, \& Poster, 2002). This is a critical issue as preparation programs and employing districts share responsibility in the training of district chief executives. Indeed, for states in which no certification has been required (Smith, 2008), questions about training, experience, and turnover are heightened even more. Nevertheless, as noted by Orr (2006):

The 2-year learning curve that some superintendents described experiencing suggests that existing preparatory experiences generally are insufficient. Instead, many stressed the need for preparatory or developmental experiences that are, as Mezirow (1991) characterized, transformative, to enable them to shift to a superintendent 
perspective to apply new frames to manage the complexity of the role and confront their role demands while determining their leadership and negotiating its scope, direction, and strategy. (p. 1398)

Despite this need articulated by superintendents via Orr's (2006) study, little is still known about the experiences of aspiring superintendents after certification but before they first become superintendents, such as which job roles these people most often hold, to what extent these roles prepare superintendents for service in differing community contexts, and to what extent these pre-superintendent roles differ across individual-level characteristics such as sex and race/ethnicity ${ }^{1}$. Further, findings from studies of building level leaders suggest that pathways to the principalship can disfavor females and educators of color (Davis et al., 2017; Crawford \& Fuller, 2015; Fuller, Hollingworth, \& An, 2016; Gates et al., 2004, 2006), and as such, it is not unreasonable to expect similar inequities within the superintendency pipeline. Given the extant knowledge supporting the importance and influence of superintendents, as well as reasonable suspicion that becoming one is an inequitable process, a closer examination of pathways into the superintendency is warranted.

\section{Purpose}

Our overarching research motivation is to determine whether, when, and who amongst educators holding superintendent certification actually become superintendents. In pursuit of this purpose, we examine the pathways of the entire population of all superintendents from one state, Texas, over an extended fifteenyear time period. Accordingly, we ask the following research questions:

1. As defined by roles held along the way and by level of employment, how do pathways into the superintendency differ by race/ethnicity and sex?

2. When controlling for personal and contextual characteristics, to what extent does the intersection of race/ethnicity and sex influence the probability of entering the superintendency?

Our first research question represents our interest in determining the roles (e.g. assistant principal, director, associate superintendent, etc.) that educators with superintendent certification are assigned to at important junctions in their career. For example, what are the common positions held by these individuals at the time of certification? What about the roles they are hired out of when they first enter the superintendency? By level of employment, we wish to know, for example, the extent to which building experience in an elementary setting as opposed to a high school setting, might impact the journey to the superintendency. Findings stemming from this first research question would not only provide more nuanced understandings of the stepping stones along the way to the superintendency, but they could also inform school districts' leadership recruitment and diversification efforts. Further, greater knowledge of administrator career trajectories could support preparation programs in quantifying their impact on the field. We pose our second research question because of what is known from the research on pathways into the principalship: that race/ethnicity and sex influence not only the likelihood (whether) of teachers becoming principals, but also the timing (when) of that transition. Conducting parallel work on the superintendency is important, as we contend that examination of the opportunities afforded to educators is integral to the broader effort to ensure that schools are socially just environments for students.

In the following sections of the paper, we begin with a discussion of our theoretical perspective, so as to shed light on the manner by which gatekeeping theory informed the foregrounding, design, and execution of the study. We then transition to a review of relevant literature, the sections of which are organized around the criteria known to impact the career movement of educational leaders. After the review of literature, we detail our methodology, including a description of the dataset and the various analyses employed. After outlining our findings, we conclude with a discussion of implications for research, policy, and practice.

\section{Theoretical Perspective}

Lewin (1947) proposed his "theory of channels and gate keepers", as a means of understanding group dynamics. He argued that the social life of organizations flows through many channels (p. 146). These channels are comprised of gates, any one of which can preclude an individual from progressing through an organization, or even entering it in the first place. Gates are ruled by gate keepers, whose attitudes and decisions about the individuals before them, are subject to bias.

Commonly referred to as gatekeeping, Lewin's theory has since been adapted across a wide variety of academic disciplines including business, medicine, communication (journalism in particular), and organizational studies (Harris \& Ogbonna, 2015; Shoemaker \& Vos, 2009). Harris and Ogbonna (2015) define the generalized form of gatekeeping theory as that "which explores how individuals and groups influence decisions regarding who or what is desirable (and thus include) or undesirable (and thus potentially exclude)" (p. 60). The connections to the present study are by now obvious, as such a theory might explain how biases influence the rise of individuals through the ranks of educational administration. Despite its tremendous potential, gatekeeping theory is seldom utilized in educational research the most notable exception being the work of Marilyn Tallerico.

Tallerico (2000a) applied gatekeeping theory to make sense of superintendent search practices, whereby candidates are understood as having to navigate a series of gates in the search process that are all ultimately influenced by norms embedded in the profession, dominant values of society, and gatekepeers' criteria (p. 21). Accordingly, Tallerico (2000a) summarized access to the superintendency thus:

Taken together, the demographics of key gatekeepers (i.e., mostly nonminority male); what we know about human similarity- 
attractiveness (i.e., the propensity to connect with those most like ourselves); and the predominance of gut feelings, chemistry, and intuition in critical interview interactions (i.e., factors that foster the introduction of subconscious bias) combine to favor male rather than female and majority rather than minority superintendent applicants. Essentially, this combination of factors presents females and people of color with more gates in the flow channels leading to the superintendency than those facing White males. (p. 37).

Tallerico goes on to argue for research methodologies that are more attentive to the fact that superintendent search and selection processes are influenced by unstated selection criteria that affect candidates at the various intersections of race and sex in different ways (p. 39).

When considering selection criteria, it is worth going back to Lewin's (1947) original theorizing on gatekeeping. He suggests that individual's measures on selection criteria exert "force" on gate keepers. This force can be positive or negative, working for or against selection (Shoemaker \& Vos, 2009, p. 14). We recognize that superintendent searches are a two sided process, whereby aspirants have to apply for, interview for, and ultimately accept (if offered) the position. While no study can account for all of the forces that shape the channels, gates, individual and organizational decisions that characterize pathways to the superintendency, we contend that the individual and contextual characteristics we address in our literature review are amongst those criteria that exert the most force upon gatekeepers along the pathway to the superintendency.

Finally, Tallerico's (2000a) argument for more attentiveness to intersectionality in superintendent research is supported by Brunner (2008) who contends that educational administration research, when not mindfully positioned, can actually reify "construction of norms that support exclusionary practices" ( $p$. 662). Put another way, methodologies that are not intentional about understanding differential impact based on race and sex could paint a "one best" approach to selecting superintendents or a preferred/ideal pathway in terms of jobs held along the way. We aim to avoid reifying a singular understanding of pathways to the superintendency by a) accounting for context, and b) breaking out our analyses by race/ethnicity and sex, including in some cases, a consideration of the intersection of race/ethnicity and sex.

\section{Relevant Literature}

As previously mentioned, there are few studies pertaining to the pre-superintendency phase of the district leadership pipeline. Those that do are primarily qualitative, and we address them here. Quantitative studies of the superintendency are primarily focused on turnover, and while our study is not concerned with that phenomenon, research in the area still describes the career movement of superintendents and could possibly shed light on transitions into the position. We comprised our literature review of subsections organized around the individual and contextual characteristics (criteria) known to exert force upon various gates in the pathways into and within the superintendency. As Grissom and Mitani (2016) attest, this particular body of literature is very limited.

\section{Individual Characteristics}

Age

Grissom and Andersen (2012) determined that age has a direct, linear relationship with superintendent turnover in California. Further, Grissom and Mitani (2016) found that when distinguishing different types of turnover in Missouri, that age was most positively related with those leaving the system. Grissom and Mitani theorized this was due to older superintendents approaching retirement age. Figures from descriptive studies support this hypothesis, as the mean superintendent age within most of these studies is in the fifties (Björk et al., 2003; Grissom \& Andersen, 2012; Kim \& Brunner, 2009). In their national study of United States superintendents, Björk, Keedy, and Gurley (2003) found that most entered the position for the first time in their mid to early forties. Kowalski, McCord, Petersen, Young, and Ellerson (2011) later reported that new superintendents were typically aged between 46 and 50 .

\section{Experience}

Given that age and experience go hand in hand, a reasonable assumption would hold that years of experience also influence the likelihood of entering the superintendency. Further, most superintendents have several years of experience in education, many of which are in campus leadership positions (Björk et al., 2003). While experience may be a common prerequisite for entering the principalship, there is no published data about how much it matters in relation to other factors. Grissom and Mitani (2016) determined that in the presence of a variety of individual and contextual characteristics, neither years of overall experience nor years of experience as a superintendent were significant predictors of any type of turnover in Missouri except for those considered leavers (again, typically retirees).

Number of years in a particular role is but one measure of experience that exerts force on gatekeepers. Positional experience and level of experience both matter as well. That is to say, in what role (e.g. principal, director, assistant superintendents, etc.) and at what level (e.g. elementary, secondary, district) an aspiring superintendent has been employed, shapes gatekeepers' impressions of aspirant fitness. As Tallerico (2000b) explains, headhunters and school board members view the high school principalship as "more complex" and "characterized by more visible pressures and more difficult problems" than the elementary or middle school principalship (p. 79). As a result, work experience at the high school level is often looked upon favorably.

\section{Education and Educational attainment}

Superintendent certification and eligibility requirements differ from state to state and change over time. A common element required for campus and district leadership certifications is an 
advanced degree. Between 2000 and 2010, the national percentage of sitting superintendents holding a doctoral degree remained at $45.3 \%$ (Kowalski et al., 2011). Analyzing a data set containing the full population of North Carolina superintendents, as well as a small, random, national sample compiled by the American Association of School Administrators (ASSA), Natkin et al. (2003) found that the higher a degree a superintendent held, the more likely they were to remain in their position. Grissom and Andersen (2012) determined that holding a doctoral degree did not significantly impact the likelihood of superintendent turnover in Missouri. They did, however, conclude that competitiveness of undergraduate degree as measured by Barron's Profile of American Colleges, was associated with turnover whereby superintendents with stronger academic preparation were more likely to remain in their positions (p. 1166).

\section{Race/ethnicity and Sex}

As of $2010,75.9 \%$ of the nation's superintendents were male and $94.0 \%$ were White. Per Grissom and Andersen (2012), Grissom and Mitani (2016), and Natkin et al. (2003), being an educator of color or female does not have a statistically significant association with superintendent turnover. This does not necessarily mean that race/ethnicity and sex do not shape pathways into the superintendency, as a) transition to the superintendent position and turnover within it are distinct portions of the district leadership pipeline, and b) White educators and males have been overrepresented in the superintendency compared to their overall share of the educator workforce (Alston, 2005; Jackson \& Shakeshaft, 2003; Kowalski et al., 2011).

Female superintendents generally have amassed more classroom teaching experience than their male counterparts (Brunner \& Grogan, 2007; Tallerico, 2000b). Because females tend to have more years of teaching experience than males, they typically enter the superintendency for the first time at an older age (Kim $\&$ Brunner, 2009). As for positions held along the way Björk et al. (2003) report that females are more likely to bypass the principalship than males. Tallerico (2000b) reports similar findings and suggests this is because of a) bias in the selection of principals that ultimately disfavor females, and b) the resultant prevalence of females who aspire to the superintendency that end up transitioning from the classroom to district central office director and coordinator roles. Relatedly, Bjork et al. (2003) found that female superintendents typically came from districtlevel curricular positions rather than as assistant/associate superintendents of finance, facilities, etc.

On the topic of district-level positions, Muñoz, Mills, Pankake, and Whaley (2014) suggest that female central office administrators in Texas may be less likely to pursue the superintendency than males, however their sample was neither representative of the state, nor was it restricted to those with superintendent certification (as ours is). In a related, qualitative study of 10 sitting and aspiring female, district-level leaders in Texas, Muñoz, Pankake, Ramalho, Mills, and Simonsson (2014) suggested that diminished motivation to pursue the superintendency can be explained, in part, by power asymmetries (i.e. sexism) and a lack of peer support and mentorship. Finally, Sperandio and Devdas (2015) through their study of district-level administrators in Pennsylvania, found that females may "self limit" their access to the superintendency via lifestyle preferences that are at odds with the demands of the position.

As for the intersection of race/ethnicity and sex, Brunner and Grogan (2007) concur with Tallerico (2000a) and suggest that, generally, there are "more hoops for women of color to jump through on their way up the administrative career ladder" ( $p$. 112). This statement is brought to life by the researchers who have been intentional in capturing the voices and experiences of female administrators of color (e.g. Alston, 2005; Angel, Killacky, \& Johnson, 2013; Brown, 2014; Horsford, 2009, 2010; Kalbus, 2000). As part of one such study, Angel, Killacky, and Johnson (2013) interviewed 10 Black, female, district-level administrators in North Carolina who identified hidden criteria and the lack of a peer support network as barriers to entering the superintendency. Angel et al. (2013) went on to describe the participants' awareness of and reactions to the "double whammy" of disadvantage that they faced due to their race/ethnicity and sex, each being dissonant with stakeholders' preferences for White males. Brown (2014) set out to investigate the impact of race/ethnicity, gender, and social politics on the promotion of Black females to the superintendency. In doing so, she echoed many of Angel et al.'s (2013) findings, highlighting the cyclical relationship between the underrepresentation of Black females in the superintendency and the general absence of a professional support/advocacy network aimed at supporting Black, female superintendents.

\section{Contextual Characteristics}

\section{District Size and Urbanicity}

The knowledge base on contextual characteristics and their influences on superintendents is primarily based in studies of sitting superintendents, rather than those aspiring to the position. While Natkin et al. (2003) determined that district size (overall enrollment) was not associated with superintendent turnover, more recent work by Grissom and Anderson (2012) suggest the largest of districts tend to have higher superintendent turnover (Grissom \& Andersen, 2012). This difference over time could be due to differences in participants/sampling as well as the onset of high-stakes accountability. Further, superintendents that leave one district for another tend to land at larger and more urbancentric districts (Grissom \& Andersen, 2012; Grissom \& Mitani, 2016). Finally, Grissom and Mitani (2016) concluded that district urbanicity had no statistically significant bearing on superintendent turnover in Missouri. When it comes to entering the superintendency for the first time, the size and urbanicity of the districts in which aspirants are employed exert force on gatekeepers (Dana \& Bourisaw, 2006; Tallerico, 2000a, 2000b). There is some logical appeal here, in that those involved in the superintendent search and selection process seek "match" between the context from which an applicant is applying and the context into which they would be hired to oversee. However, and 
as Tallerico (2000b) forewarns, there is risk in over-emphasizing such match, as it can reify the taken for granted value of previous experiences and discard the fact that leadership skills can be acquired through a variety of experiences and contexts (p. $81)$.

\section{Student Characteristics and Achievement}

Both Grissom and Andersen (2012) and Natkin et al. (2003) found that higher percentages of students eligible for free or reduced-price lunch was associated with greater superintendent turnover. With regards to student race/ethnicity, Grissom and Andersen (2012) determined that Hispanic enrollment had a negative association with turnover, while African American enrollment was not statistically significant in its association with California superintendent turnover. Interestingly, student test scores and their changes were not a factor for turnover in the studies by Grissom and Andersen (2012) and Grissom and Mitani (2016).

In summary, the literature on factors influencing transitions into the superintendency is sparse. From the research that is available, it is clear that a variety of personal and contextual characteristics impact turnover likelihood and gatekeeper's impressions of aspiring superintendents. Accordingly, we sought to account for as many of these criteria as possible in our analyses, the latter of which we describe in the following section.

\section{METHODS:}

\section{Data}

This study is a secondary data analysis of Texas public school educators who obtained superintendent certification for the first time between the 2000-01 and 2014-15 school years. Over the course of those 15 academic years, all educators observed for this study were required to have obtained a master's degree and completed a state-approved superintendent certification program.

Our dataset, which has information acquired from the Texas Education Agency (TEA) and the National Center for Education Statistics (NCES) Common Core of Data (CCD), contains 26,071 observations of 4,813 unique individuals who were certified for the district-level superintendent leadership role from 2000-01 - 2014-15 and were employed in Texas public schools, making ours one of the largest datasets examined to date in this domain. For each individual in our final data set, we have both fixed and time-varying measures of individual characteristics (e.g. race/ethnicity/ethnicity, sex, age, years of experience, education, etc.) and workplace characteristics (e.g. district size, urbanicity, accountability rating, etc.). Table 1 contains the proportional representation of these measures across all observations in the dataset, as well as those at two important junctures: time of initial superintendent certification, or entry observations, and time of first appointment as a school district superintendent, or event observations. Table 2 reflects the percentage distribution, at time of certification, of educator race/ethnicity and sex across three important contexts: district urbanicity, district size, and level of employment. The number and availability of superintendent positions varies based upon these contexts, so it was important to convey this information. We review the major themes stemming from tables 1 and 2 in the findings section of this paper.

\section{Analysis}

\section{Alluvial Diagram}

To answer our first research question, we sought to establish a visual representation of pathways into the superintendency. Researchers typically relay such information via prose or a table with descriptive figures. Given that we are interested in multiple junctures along the pathway and in discerning a variety of different avenues into the superintendency, we felt a visual display would be both methodologically apropos and responsive to Brunner's (2008) aforementioned call for broadened understandings.

We draw upon the metaphor of stepping-stones in a walkway as a means for understanding the various roles held by educators along the pathway to the superintendency. Our focus is on two specific stepping-stones: role at time of certification, and role held in the year prior to becoming a superintendent. In other words, 1) the roles that eventual superintendents had when they first obtained the requisite certification, and 2) the roles they were hired out of when they first became superintendents.

First developed by Rosvall and Bergstrom (2010), alluvial diagrams are named for alluvial fans, a geological term for the patterned deposits of sediment created by the movement of water. Just like alluvial fans, alluvial diagrams are comprised of many pathways that often cross one another. Alluvial diagrams are comprised of horizontal bands that depict proportional movement between categorical nodes. Flows and gates, central aspects of gatekeeping, are the theoretical equivalents of bands and nodes. In the present study, we show the proportional movement of eventual superintendents from role at certification to role immediately prior to becoming a superintendent. The thickness of each individual band indicates the number of educators that took that particular pathway in proportion to all others. We used RAW (http://raw.densitydesign.org/), to create the diagrams.

\section{Life Table}

Before determining how personal and contextual characteristics influence the probability of entering the superintendency (research question two) we deem it necessary to first understand the overall likelihood of becoming a superintendent in the years following certification. To do so, we compiled a life table that reflects the career pathways of the 4,813 educators under study. Life tables are the most basic and traditional form of survival analysis. Through the life table, we report how many educators entered the superintendency, continued in a non-superintendent role, or left the Texas public education system (right-censored) in each period. Periods are measured in academic years, but are not calendar-year specific. For example, period 0 for all study participants is the academic year in which they first obtained 
superintendent certification. For a particular participant, period 0 might correspond with the 2003-04 academic year, while another participant might have obtained their first superintendent certification in 2008-09. Period 1 represents the academic year immediately following that in which the participants first obtained superintendent certification, again, without regard for calendar year; period 2 would be the following academic year, and so on. This allowance of scattered starting periods is a hallmark of event history analysis that provides intuitive appeal and methodological advantage over retrospective methods.

\section{Discrete Time Hazard Model}

Given the conditional time dependent nature of modeling the probability of experiencing the "hazard" of moving into the superintendency, we added further context to our response to research question two via a discrete-time hazard (DTH) model framework (Bowers, 2010; Davis et al. 2017; Singer \& Willett, 2003). The DTH model is a logistic regression in which the dependent variable is the probability of each individual entering the superintendency within a given period (measured in years) after certification, estimating the relationship with periodspecific covariates, as well as variables representing individual and contextual characteristics. In keeping with Tallerico's (2000a) adaptation of gatekeeping theory whereby various criteria that define candidate experience exert force on powerholders' impressions of aspiring superintendents, the independent variables we selected coincide with the individual and contextual characteristics described in our review of relevant literature. The individual characteristics include age, age squared, whether or not an individual has obtained a doctoral degree, number of concurrent years employed with present district, number of years in the Texas public education system (and the square of that number), race/ethnicity, sex, and the interaction of race/ethnicity and sex. A final individual characteristic we control for is level of role at time of certification. There are four possible values for this characteristic: elementary, middle, high, district (employed in central office / district administration), or other (most of these instances were of employment on a campus that housed a mixture elementary and secondary grades).

The contextual characteristics are time lagged by one year to account for gatekeepers' perceptions of applicants, as influenced by the latter's work experience. This decision reflects our previous discussion of gatekeepers' proclivity to seek match between the contexts that aspirants have worked in and the ones they are applying for. Included are measures of student race/ethnicity and socioeconomic status, district size, district urbanicity, and a dichotomous measure of whether or not the district met Texas accountability standards. Because many aspiring superintendents are not employed in campus level roles, all contextual characteristics are measured at the district level.

All continuous measures were standardized (z-scored). Loglinear models are sensitive to multicollinearity in that resultant coefficients can be unstable and unreliable (Long, 1997). So as to avoid multicollinearity, we calculated variance inflation factors (VIFs) for all independent variables. There is no universally accepted guide to what constitutes an unacceptably high VIF, however, (O'Brien, 2007) identifies common rules of thumb suggesting that VIFs over 4 and over 10 are problematic. All computed VIFs were well below four.

We utilized a stepwise model building approach. The difference between our first and second model is the inclusion of a set of dummy variables representing level of employment at time of certification. The equation for our full, final DTH model is as follows:

$\operatorname{logit} h\left(t_{j}\right)=\left[\alpha_{1} D_{1}+\alpha_{2} D_{2}+\cdots \alpha_{13} D_{13}\right]+\beta_{1}$ age $+\beta_{2}$ age squared $+\beta_{3}$ doctoral degree $+\beta_{4}$ years with district + $\beta_{5}$ years as educator $+\beta_{6}$ years as educator squared + $\beta_{7-10}$ level of role $+\beta_{11-13}$ race/ethnicity dummies + $\beta_{14}$ female $+\beta_{15-17}$ race/ethnicity and female interactions $+\beta_{18-20}$ district student body characteristics $+\beta_{20-22}$ district size $+\beta_{23-25}$ district urbanicity $+\beta_{26}$ district accountability outcome

The $\alpha$ 's represent each period in the study, while the $\beta$ 's are slope parameters representing the influence of each independent variable on the relative probability of entering the superintendency. Period 14 observations were dropped because no one made the transition at that point.

Unlike in linear regression, logistic regression coefficients are expressed in $\log$ odds format. Alongside the log odds coefficients, we include odds ratios in our results table. Odds ratios represent the change in the odds of becoming a superintendent that an individual would experience with a 0 to 1 increase in the independent variable of interest (or no to yes for dichotomous, categorical variables). The reference or comparison group in our discrete-time hazard model is White males, since they are the largest race/ethnicity and sex intersection group amongst those obtaining certification $(40.25 \%$ of period entry observations).

As the state of Texas changed from the Texas Assessment of Academic Skills (TAAS) to the Texas Assessment of Knowledge and Skills (TAKS) to the presently used State of Texas Assessment of Academic Readiness (STAAR) accountability regimes, there were two transition years (2002-03 and 2011-12) in which district accountability ratings were not made available. This absence of ratings introduced potential missing data concerns, as district accountability rating is one of the covariates in the DTH model. Because $61.5 \%$ of participants were employed in at least one of those school years, observing whether or not they became superintendents during that time is critically important to accurately calculating overall hazard and 
Table 1: Descriptives

\begin{tabular}{|c|c|c|c|c|c|c|c|c|c|c|c|c|}
\hline & \multicolumn{4}{|c|}{ All observations } & \multicolumn{4}{|c|}{$\begin{array}{l}\text { Initial certification } \\
\text { (Entry observations) }\end{array}$} & \multicolumn{4}{|c|}{$\begin{array}{l}\text { Entered superintendency } \\
\text { (Event observations) }\end{array}$} \\
\hline & Mean & SD & Min & $\operatorname{Max}$ & Mean & SD & Min & Max & Mean & SD & Min & $\operatorname{Max}$ \\
\hline \multicolumn{13}{|l|}{ Individual characteristics } \\
\hline Female & 0.478 & 0.500 & 0 & 1 & 0.476 & 0.499 & 0 & 1 & 0.229 & 0.421 & 0 & 1 \\
\hline White & 0.743 & 0.437 & 0 & 1 & 0.732 & 0.443 & 0 & 1 & 0.850 & 0.358 & 0 & 1 \\
\hline Latinx & 0.151 & 0.358 & 0 & 1 & 0.150 & 0.357 & 0 & 1 & 0.112 & 0.315 & 0 & 1 \\
\hline Black & 0.086 & 0.280 & 0 & 1 & 0.096 & 0.295 & 0 & 1 & 0.025 & 0.158 & 0 & 1 \\
\hline Asian & 0.005 & 0.069 & 0 & 1 & 0.006 & 0.076 & 0 & 1 & 0.001 & 0.035 & 0 & 1 \\
\hline Other & 0.015 & 0.124 & 0 & 1 & 0.016 & 0.127 & 0 & 1 & 0.012 & 0.110 & 0 & 1 \\
\hline Female and White & 0.338 & 0.473 & 0 & 1 & 0.329 & 0.470 & 0 & 1 & 0.193 & 0.395 & 0 & 1 \\
\hline Latina & 0.079 & 0.270 & 0 & 1 & 0.078 & 0.269 & 0 & 1 & 0.030 & 0.172 & 0 & 1 \\
\hline Female and Black & 0.050 & 0.218 & 0 & 1 & 0.057 & 0.232 & 0 & 1 & 0.005 & 0.070 & 0 & 1 \\
\hline Female and Asian & 0.003 & 0.053 & 0 & 1 & 0.003 & 0.054 & 0 & 1 & 0.000 & 0.000 & 0 & 0 \\
\hline Female and Other & 0.008 & 0.087 & 0 & 1 & 0.009 & 0.093 & 0 & 1 & 0.001 & 0.035 & 0 & 1 \\
\hline Male and White & 0.404 & 0.491 & 0 & 1 & 0.402 & 0.490 & 0 & 1 & 0.657 & 0.475 & 0 & 1 \\
\hline Male and Latinx & 0.072 & 0.259 & 0 & 1 & 0.072 & 0.258 & 0 & 1 & 0.081 & 0.273 & 0 & 1 \\
\hline Male and Black & 0.036 & 0.186 & 0 & 1 & 0.039 & 0.194 & 0 & 1 & 0.021 & 0.142 & 0 & 1 \\
\hline Male and Asian & 0.002 & 0.044 & 0 & 1 & 0.003 & 0.054 & 0 & 1 & 0.001 & 0.035 & 0 & 1 \\
\hline Male and Other & 0.008 & 0.089 & 0 & 1 & 0.008 & 0.087 & 0 & 1 & 0.011 & 0.104 & 0 & 1 \\
\hline Doctoral degree $(\mathrm{Y} / \mathrm{N})$ & 0.147 & 0.354 & 0 & 1 & 0.080 & 0.271 & 0 & 1 & 0.170 & 0.376 & 0 & 1 \\
\hline Age & 45.891 & 7.873 & 24 & 75 & 42.808 & 7.549 & 24 & 71 & 45.568 & 7.012 & 29 & 74 \\
\hline Years in education & 18.376 & 7.917 & 0 & 49 & 15.381 & 7.414 & 0 & 49 & 17.579 & 8.858 & 0 & 43 \\
\hline Years with district & 8.910 & 8.051 & 0 & 44 & 7.374 & 7.031 & 0 & 40 & 5.211 & 7.651 & 0 & 41 \\
\hline Level at time of cert - Elementary & 0.225 & 0.417 & 0 & 1 & 0.218 & 0.413 & 0 & 1 & 0.150 & 0.358 & 0 & 1 \\
\hline Level at time of cert - Middle & 0.191 & 0.393 & 0 & 1 & 0.181 & 0.385 & 0 & 1 & 0.121 & 0.327 & 0 & 1 \\
\hline Level at time of cert - High & 0.300 & 0.458 & 0 & 1 & 0.297 & 0.457 & 0 & 1 & 0.371 & 0.483 & 0 & 1 \\
\hline Level at time of cert - District & 0.225 & 0.417 & 0 & 1 & 0.243 & 0.429 & 0 & 1 & 0.263 & 0.440 & 0 & 1 \\
\hline Level at time of cert - Other & 0.053 & 0.224 & 0 & 1 & 0.060 & 0.238 & 0 & 1 & 0.093 & 0.291 & 0 & 1 \\
\hline \multicolumn{13}{|l|}{ District Controls } \\
\hline Enrollment 1-1000 & 0.194 & 0.395 & 0 & 1 & 0.218 & 0.413 & 0 & 1 & 0.636 & 0.481 & 0 & 1 \\
\hline Enrollment 1001-5000 & 0.308 & 0.462 & 0 & 1 & 0.307 & 0.461 & 0 & 1 & 0.249 & 0.433 & 0 & 1 \\
\hline Enrollment 5001-25000 & 0.250 & 0.433 & 0 & 1 & 0.234 & 0.423 & 0 & 1 & 0.092 & 0.290 & 0 & 1 \\
\hline Enrollment 25001+ & 0.248 & 0.432 & 0 & 1 & 0.242 & 0.428 & 0 & 1 & 0.023 & 0.150 & 0 & 1 \\
\hline Urbanicity - rural & 0.540 & 0.498 & 0 & 1 & 0.528 & 0.499 & 0 & 1 & 0.795 & 0.404 & 0 & 1 \\
\hline Urbanicity - town & 0.115 & 0.319 & 0 & 1 & 0.110 & 0.313 & 0 & 1 & 0.101 & 0.301 & 0 & 1 \\
\hline Urbanicity - suburb & 0.163 & 0.370 & 0 & 1 & 0.181 & 0.385 & 0 & 1 & 0.057 & 0.232 & 0 & 1 \\
\hline Urbanicity - city & 0.181 & 0.385 & 0 & 1 & 0.181 & 0.385 & 0 & 1 & 0.047 & 0.212 & 0 & 1 \\
\hline$\%$ Students econom. disadv. & 0.557 & 0.200 & 0 & 1 & 0.545 & 0.205 & 0 & 1 & 0.555 & 0.186 & 0 & 1 \\
\hline$\%$ Students Black & 0.123 & 0.138 & 0 & 0.956 & 0.125 & 0.140 & 0 & 0.912 & 0.076 & 0.118 & 0 & 0.869 \\
\hline$\%$ Students Latinx & 0.392 & 0.268 & 0 & 1 & 0.378 & 0.268 & 0 & 1 & 0.325 & 0.278 & 0 & 1 \\
\hline$\%$ Students White & 0.450 & 0.274 & 0 & 1 & 0.465 & 0.280 & 0 & 1 & 0.578 & 0.278 & 0 & 1 \\
\hline Met Accountability Standard & 0.978 & 0.146 & 0 & 1 & 0.981 & 0.135 & 0 & 1 & 0.976 & 0.154 & 0 & 1 \\
\hline$N$ & 26,071 & & & & 4,813 & & & & 824 & & & \\
\hline
\end{tabular}

survival functions. Therefore, we used all other variables in the data set and Stata's (StataCorp, 2013) multiple imputation feature to impute missing values so that observations from those two academic years could be included. After imputing the accountability ratings, greater than $99 \%$ of all observations in the final data set contributed to the discrete-time hazard model, as less then $1 \%$ of observations had even a missing value for any of the variables included.

\section{FINDINGS:}

Before reporting the specific findings associated with each research question, we offer a review of descriptive figures concerning the individuals under study. The first main finding as shown in Table 1, is that out of 4,813 unique Texas public school educators who obtained superintendent certification between the years 2000-2001 and 2014-2015, 824 became superintendents $(17.09 \%)$ in the time they were observed ${ }^{2}$. Table 1 indicates that educators entering the superintendency are roughly three years older than those who obtain certification. Similarly, doctoral degree holders are more represented amongst new superintendents than amongst educators obtaining certification. As stands to reason, educators who become superintendents have been in education slightly longer than those obtaining the requisite certification. However, those who become 
Table 2: Percentage Distribution of Educator Race/Ethnicity and Sex across Key Contexts

\begin{tabular}{lrrrrrrr} 
& \multicolumn{3}{c}{ Race/Ethnicity } & \multicolumn{2}{c}{ Sex } \\
& Asian & Black & Latinx & Other & White & Female & Male \\
\hline District Urbanicity & & & & & & & \\
$\quad$ Rural & 0.37 & 5.41 & 9.95 & 1.38 & 82.89 & 41.88 & 58.12 \\
$\quad$ Town & 0.39 & 5.62 & 14.53 & 1.94 & 77.52 & 43.41 & 56.59 \\
$\quad$ Suburb & 0.92 & 11.43 & 14.45 & 1.71 & 71.48 & 54.27 & 45.73 \\
$\quad$ City & 0.64 & 18.23 & 28.88 & 1.93 & 50.32 & 54.69 & 45.31 \\
District Enrollment & & & & & & & \\
0-1000 & 0.19 & 2.39 & 6.39 & 1.34 & 89.69 & 33.02 & 66.98 \\
1001-5000 & 0.20 & 5.08 & 9.75 & 1.69 & 83.28 & 46.17 & 53.83 \\
5001-25000 & 0.44 & 12.27 & 19.56 & 1.69 & 66.04 & 51.82 & 48.18 \\
$\quad$ 25001 & 1.55 & 19.26 & 25.11 & 1.81 & 52.28 & 58.47 & 41.53 \\
Level of Employment & & & & & & & \\
$\quad$ Elementary & 0.86 & 10.09 & 17.51 & 1.43 & 70.12 & 62.89 & 37.11 \\
$\quad$ Middle & 0.69 & 13.10 & 13.68 & 1.84 & 70.69 & 41.84 & 58.16 \\
$\quad$ High & 0.63 & 9.23 & 12.45 & 1.89 & 75.80 & 32.73 & 67.27 \\
$\quad$ Other & 0.34 & 5.50 & 4.81 & 2.06 & 87.29 & 33.68 & 66.32 \\
$\quad$ District & 0.26 & 8.03 & 19.47 & 1.28 & 70.96 & 59.78 & 40.22 \\
\hline
\end{tabular}

superintendents have fewer concurrent years of employment with their district than those who obtain certification, suggesting that superintendents are not necessarily "homegrown". Educators from smaller and rural districts have greater representation amongst those who become superintendents than they do amongst those who obtain certification. Table 1 also indicates concerning differences in the proportional representation of sex and race/ethnicity amongst those obtaining certification compared to those entering the superintendency. More specifically, males and White educators are overrepresented amongst the latter group. All intersections of race/ethnicity with female have lower representation amongst those entering the superintendency than amongst those obtaining certification. Further, White and Latinx males have greater representation amongst those becoming superintendents than those obtaining certification. Finally, those who were employed in high school or district level roles at the time of earning certification, have greater representation amongst those entering the superintendency.

Table 2 indicates that the race/ethnicity and sex of educators at time of superintendent certification is unequally distributed across district context and school-level. Generally, educators of color and females are overrepresented in urban and large districts (enrollment greater than 25,000) in comparison to their overall share of those with superintendent certification. Conversely, white educators and males are overrepresented in rural and small districts (enrollment of less than 1,000). With regards to level of employment at time of certification, Asians are underrepresented at the district level. Black educators are overrepresented at the middle school level, Latinx educators are overrepresented at the district level, and White educators are overrepresented at "other" types of campuses (which most often Davis \& Bowers (2019) are small and/or rural). Females are underrepresented at the high school level and overrepresented at the elementary and district levels. The inverse is true for males, who are overrepresented at the high school level and underrepresented at the elementary and district levels.

\section{Research Question 1}

The main findings for our first research question are organized around a group of four alluvial diagrams depicted in figures 1 through 4 . We begin with figure 1 , which contains an alluvial diagram representing the full study population's pathways into the superintendency. We collapsed roles into 7 categories: teacher, assistant principal, principal, other campus-level role, assistant superintendent, other district-level role, and of course, superintendent. The diagram is comprised of three junctures in the superintendency pipeline that are represented by the vertical lines, which are known as nodes. These alluvial diagrams represent only those Texas educators who obtained their first superintendent certification between 2000-01 and 2014-15 and eventually became superintendents within that same timeframe a total of 824 unique individuals. The left-most node represents the roles in which those individuals were employed when they gained superintendent certification. The middle node represents the role they were employed in the academic year before becoming a superintendent: this can also be thought of as the job they were hired out of to become a superintendent for the first time. The right-most node, of course, represents the superintendency, as all pathways terminate there. 
Figure 1: Full Population Alluvial

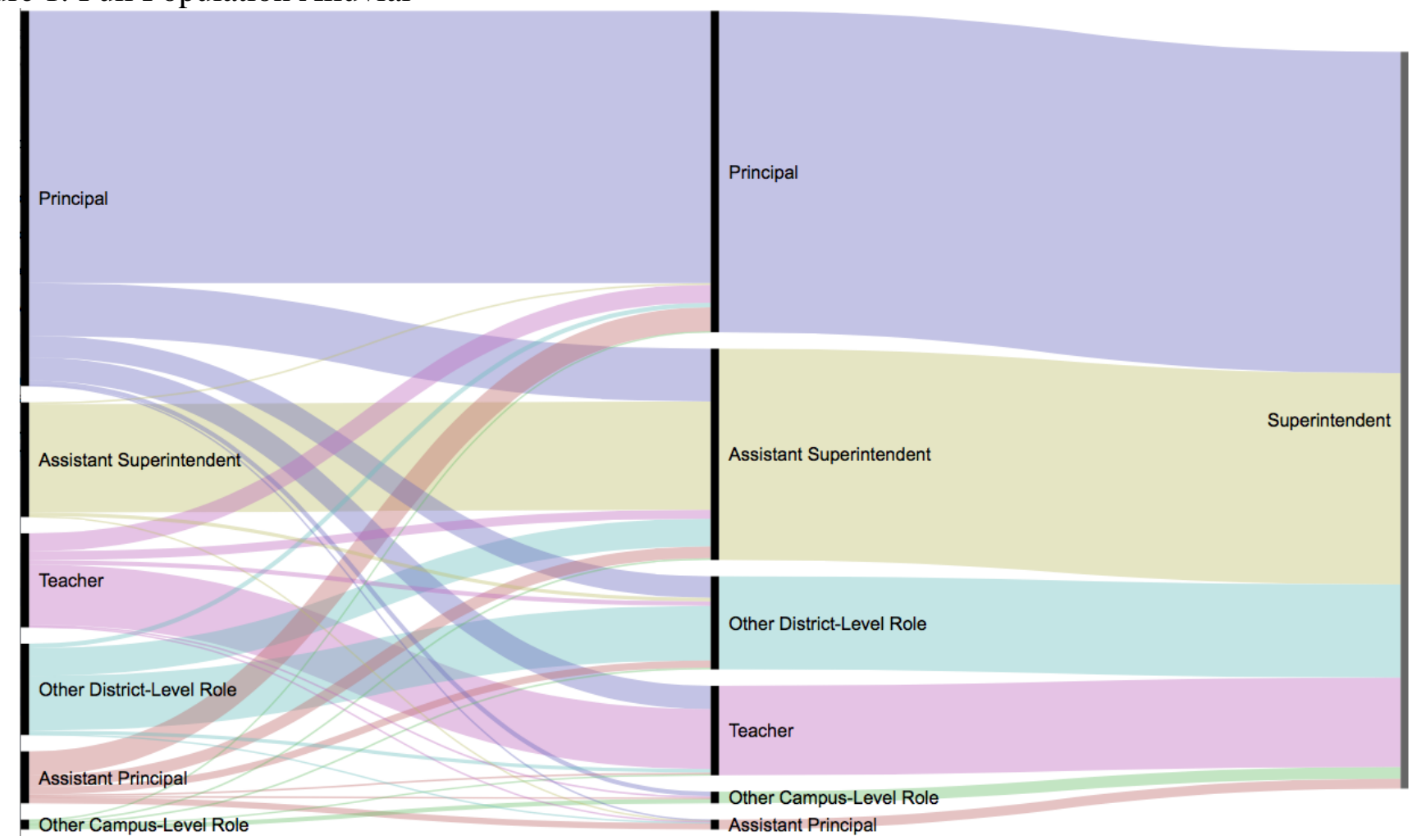

\begin{tabular}{lrr} 
& \multicolumn{2}{c}{$\begin{array}{c}\text { Role when Hired into } \\
\text { Superintendency }\end{array}$} \\
\hline Assistant Principal & Role at Certification & $1.34 \%$ \\
Assistant Superintendent & $7.16 \%$ & $28.68 \%$ \\
Other Campus-Level Role & $15.53 \%$ & $1.58 \%$ \\
Other District-Level Role & $1.33 \%$ & $12.64 \%$ \\
Principal & $12.38 \%$ & $43.62 \%$ \\
Teacher & $50.85 \%$ & $12.15 \%$ \\
\hline
\end{tabular}

The 823 individuals represented in figure 1 traveled 32 different pathways to the superintendency. The most common pathway starts with obtaining certification while in the principalship and concludes with being hired out of that same position and into the superintendency $(36.94 \%)$. The second most traveled pathway begins with and continues through the assistant superintendency (14.70\%). These two progressions combine to account for greater than half of all superintendent pathways. Further, 57.2\% of eventual superintendents were employed in campus level positions at the time of certification and hiring into the superintendency. Put another way, the majority of Texas superintendents bypass district-level administrative roles (central office) at these two nodes. As a point of comparison, Björk et al. (2003) determined via their unweighted analysis of national data, that $31.2 \%$ of respondents bypassed central office altogether. Finally, and of surprise to us, was the proportion of Texas superintendents hired out of non-administrative campus-level positions (13.73\%). We determined that, just as Kowalski et al.
(2011) did in their national study, most of these instances occurred in small and rural districts. Still, the vast majority $(86.27 \%)$ of eventual superintendents were either head principals, "other district-level" employees, or assistant superintendents in the academic year immediately preceding that in which they first became a superintendent.

Figure 2 separates pathways by sex. The common most pathway for females starts and stays within the assistant superintendency $(23.83 \%)$, closely followed by starting and staying within the principalship (22.22\%). Males were far more likely to begin and stay at the campus level than were females, as $41.32 \%$ earned certification during and were hired out of the principalship. Starting and staying within the assistant superintendency was the second most common pathway for males, yet it only accounted for $11.99 \%$ of that group. 
Figure 2: Alluvials by Sex

Females

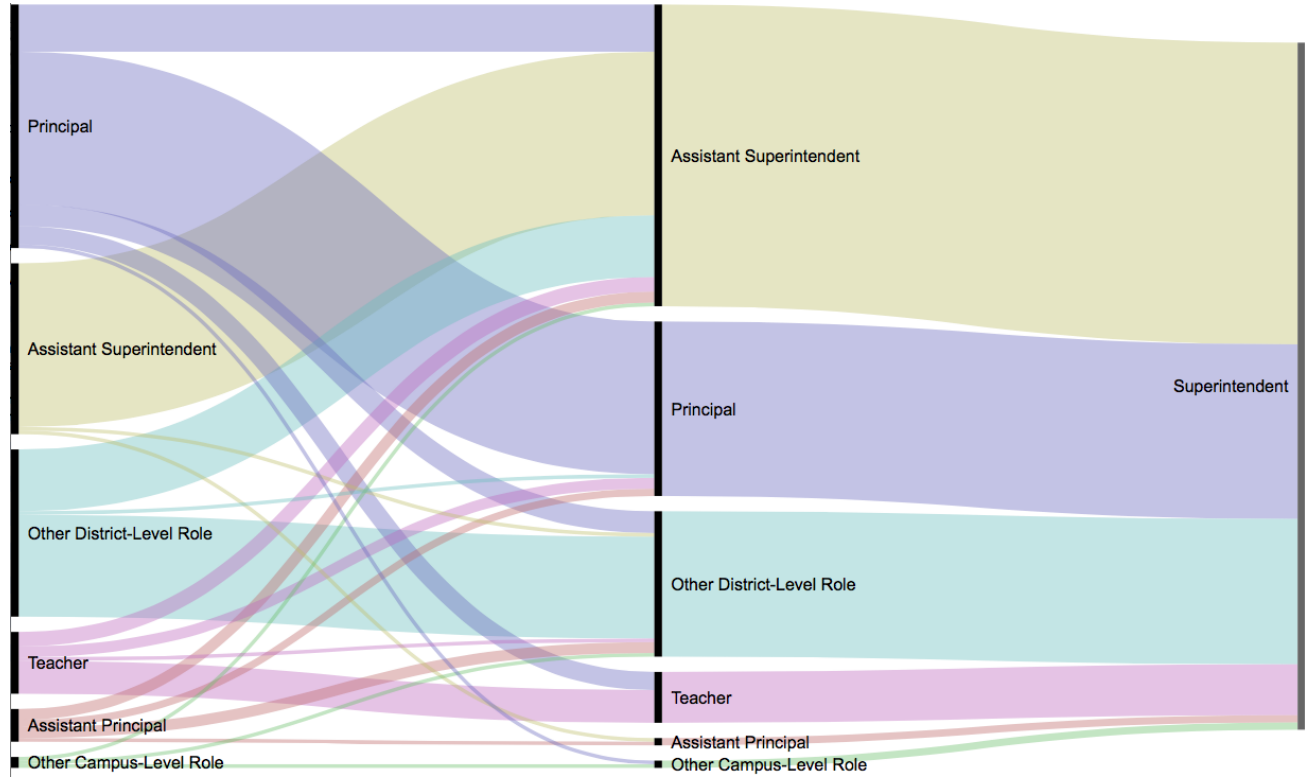

Males




Figure 3: Alluvials by Race/Ethnicity

White

\section{Of Color}
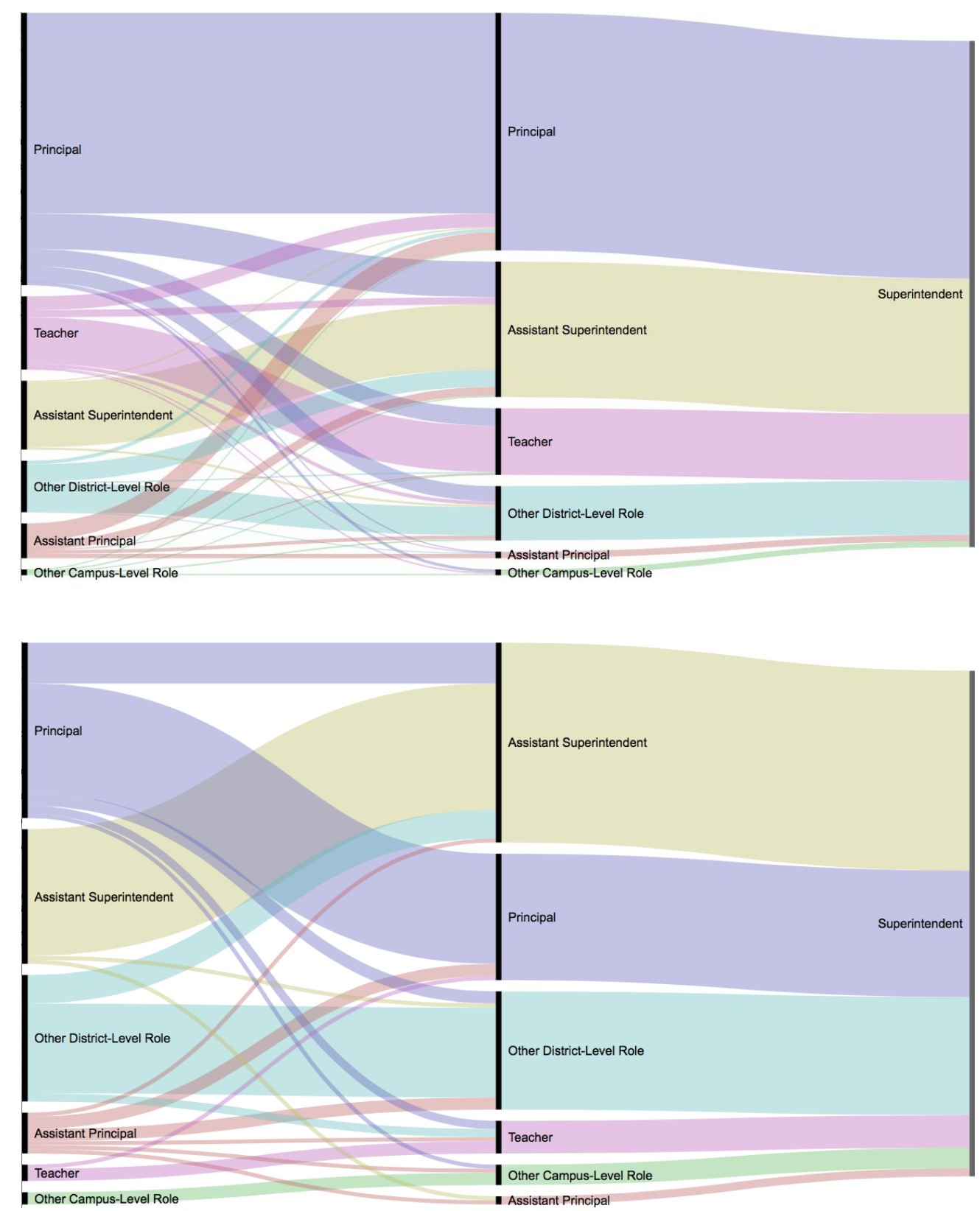

Figure 3 separates pathways by whether or not the educators are White. Of White superintendent certification holders whom eventually enter the superintendency, $39.63 \%$ do so via the principalship. The next largest pathway for White educators begins and remains in the assistant superintendency (12.83\%). These pathways are flipped for educators of color where most (25\%) begin and remain in the assistant superintendency, while the second largest group begin and travel through the principalship (21.77). Interestingly, $17.74 \%$ of educators of color that eventually become superintendents begin in a district level role other than the assistant superintendency.
Differences in the pathways to the superintendency around race/ethnicity and sex raise questions about the influence of the contexts we investigated through table 2 , most notably, the school-level of employment of elementary, middle school, or high school. To investigate this influence, Figure 4 separates pathways by school-level of role, using the same values included in the discrete-time hazard model, as with Figures 1-3, the left node indicates school-level role at time of certification, and the central node the school-level that the superintendent was hired out of. First time superintendents are overwhelmingly hired out of district-level or high school-level roles $(63.40 \%$ of observations), a finding in line with Tallerico's (2000b) 
Figure 4: Alluvial by Level of Role

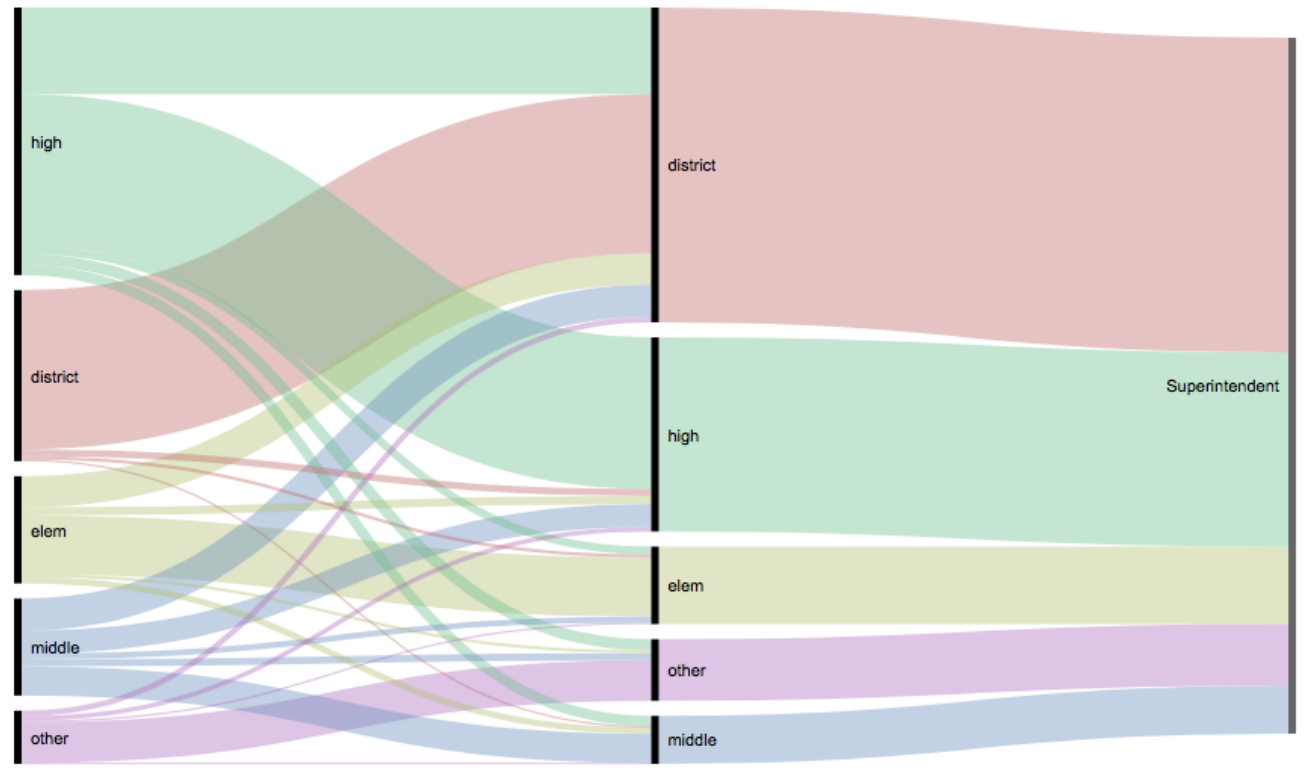

conclusion that gatekeepers value certain work experience, particularly the high school principalship.

If we presume that experience in particular roles is central to how one demonstrates their readiness for the superintendency based on the criteria including work experience in particular roles and at particular levels, then it seems, based on our analyses and the research, that White educators and males seem to demonstrate readiness at the campus level more often than educators of color and females. Put another way, and echoing Brunner and Grogan's (2007) sentiment of "more hoops", it seems that females and educators of color have to put in time in district level roles (most notably the assistant superintendency) before successfully becoming superintendents. It is important to note that these alluvial diagrams do not account for the distribution of race/ethnicity and sex across district varying typologies. Because district size (and often urbanicity) determine district leadership structures, and therefore the number and availability of vacant superintendencies, interpretation of these diagrams must take these facts into account.

\section{Research Question 2}

Before moving to our discrete-time hazard model, we determine on a very broad level, whether and when certificate holders become superintendents. We do this by presenting the unconditional survival analysis represented in the life table (Table 3). Three important trends stand out, first of which being that hazard is quite low, whereas five percent or less of certificate holders enter the superintendency in any given period. Second, peak hazard occurs immediately after certification, and generally falls over time. Finally, hazard begins to approach zero after year 10.

We also offer a visual representation of hazard, whereby hazard is measured along the $\mathrm{Y}$ axis and plotted over periods across the $\mathrm{X}$ axis. Figures 5 and 6 are restricted to the first 10 periods and are separated by sex and whether or not the educator is White, respectively. What is clear from these figures is that males and White educators have substantially higher probabilities of becoming a superintendent in virtually any given period after certification than their female and educator of color counterparts, respectively. Figure 7 contains 4 separate lines representing the intersections of White/of Color with sex. The takeaway here is that intersectionality matters: the likelihood of males entering the superintendency is generally greater than that of females, however, within this separation, there is a clear effect of race/ethnicity. For example, males of color are generally more likely to become superintendents than females (White or of color), but are far less likely than White males to enter the superintendency, particularly in the early years after certification. And while White females are generally less likely than males (White or of color) to enter the superintendency, they are more likely than females of color to make the transition.

It is important to note that these hazard plots do not control for contextual characteristics such as district size, urbanicity, and the like. Thus, we proceeded to analyze the data using a discrete time hazard model to examine the conditional probability of a certified educator becoming a superintendent in each period controlling for the change in the conditional risk set as people become superintendents over time and thus are no longer "at risk" of becoming a superintendent. It is worth noting that exploration of alternative specifications of time is advised when hazard is near zero in some time periods and when the risk set becomes small in later periods (Singer \& Willett, 2003). Both instances apply to this study, therefore we examined linear, quadratic, and cubic treatments of time. By comparing measures of deviance, we determined that including a unique variable representing each time period represented the best fit of the data, despite the additional terms that come with doing so. 
Table 3: Life Table

Not a Became

Superintendent at Superintendent Hazard Survival

\begin{tabular}{rrrcccc}
\multicolumn{1}{r}{ Period } & Interval & Beginning of Year & During the Year & Censored & Function & Function \\
\hline 0 & 0,1 & 4,813 & - & 519 & 0.000 & 1.000 \\
1 & 1,2 & 4,294 & 217 & 438 & 0.051 & 0.950 \\
2 & 2,3 & 3,639 & 152 & 437 & 0.042 & 0.910 \\
3 & 3,4 & 3,050 & 107 & 423 & 0.035 & 0.878 \\
4 & 4,5 & 2,520 & 93 & 371 & 0.037 & 0.846 \\
5 & 5,6 & 2,056 & 71 & 285 & 0.035 & 0.816 \\
6 & 6,7 & 1,700 & 70 & 302 & 0.041 & 0.783 \\
7 & 7,8 & 1,328 & 35 & 227 & 0.026 & 0.762 \\
8 & 8,9 & 1,066 & 27 & 227 & 0.025 & 0.743 \\
9 & 9,10 & 812 & 20 & 175 & 0.025 & 0.725 \\
10 & 10,11 & 617 & 17 & 201 & 0.028 & 0.705 \\
11 & 11,12 & 399 & 9 & 129 & 0.023 & 0.689 \\
12 & 12,13 & 261 & 4 & 118 & 0.015 & 0.678 \\
13 & 13,14 & 139 & 2 & 137 & 0.014 & 0.668
\end{tabular}

Figure 5: Hazard of Entering Superintendency by Sex

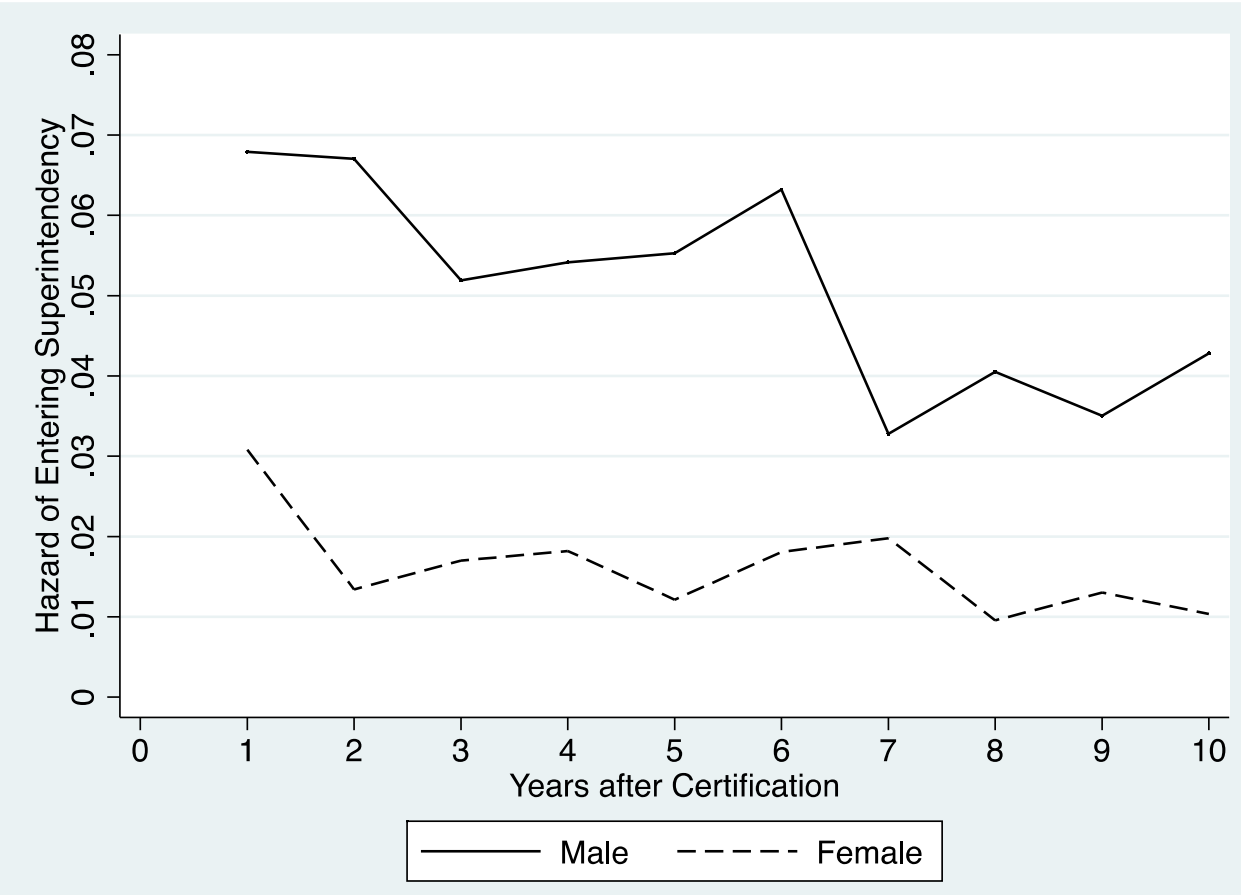


Figure 6: Hazard of Entering Superintendency by Race/Ethnicity

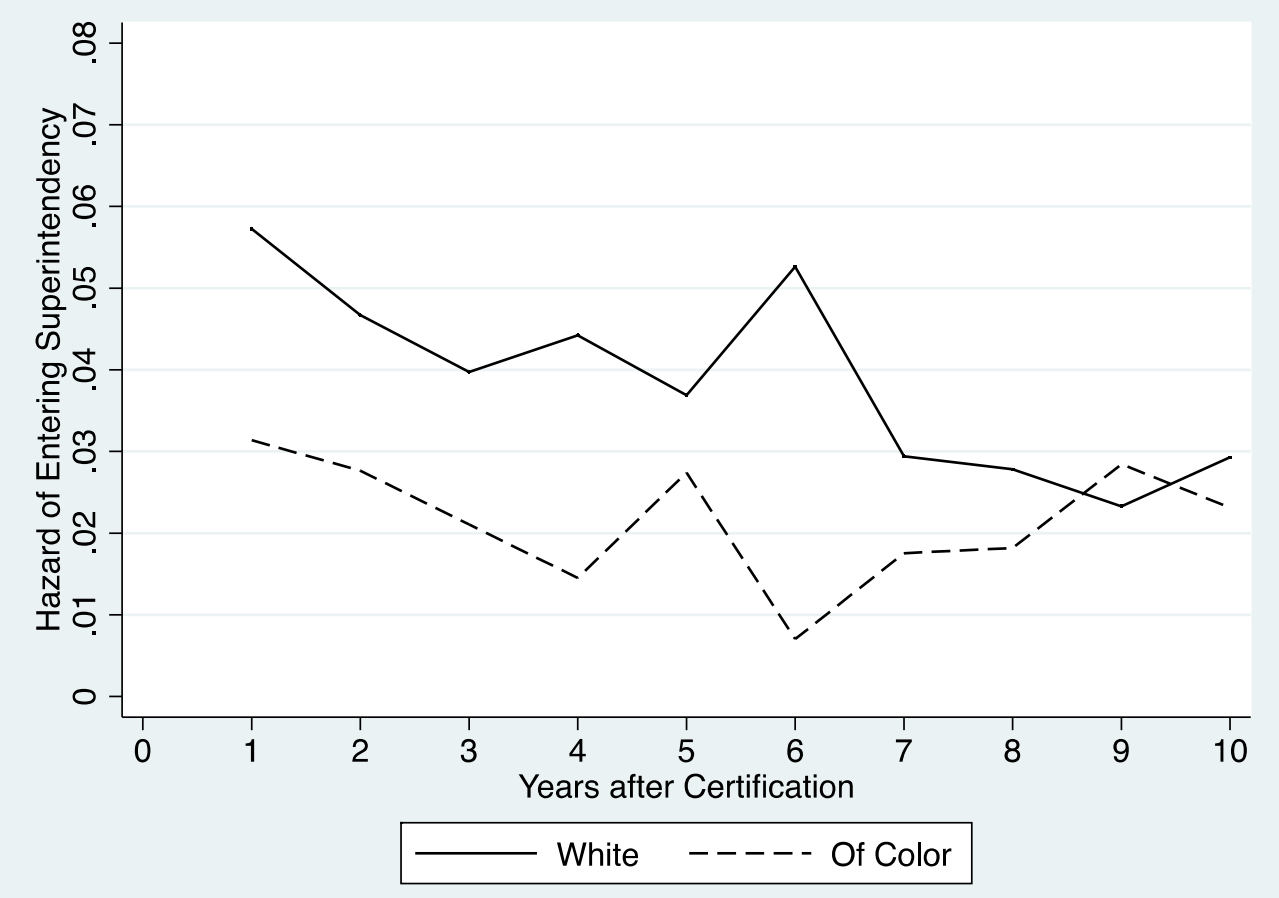

Figure 7: Hazard of Entering Superintendency by Intersection of Sex and Race/Ethnicity

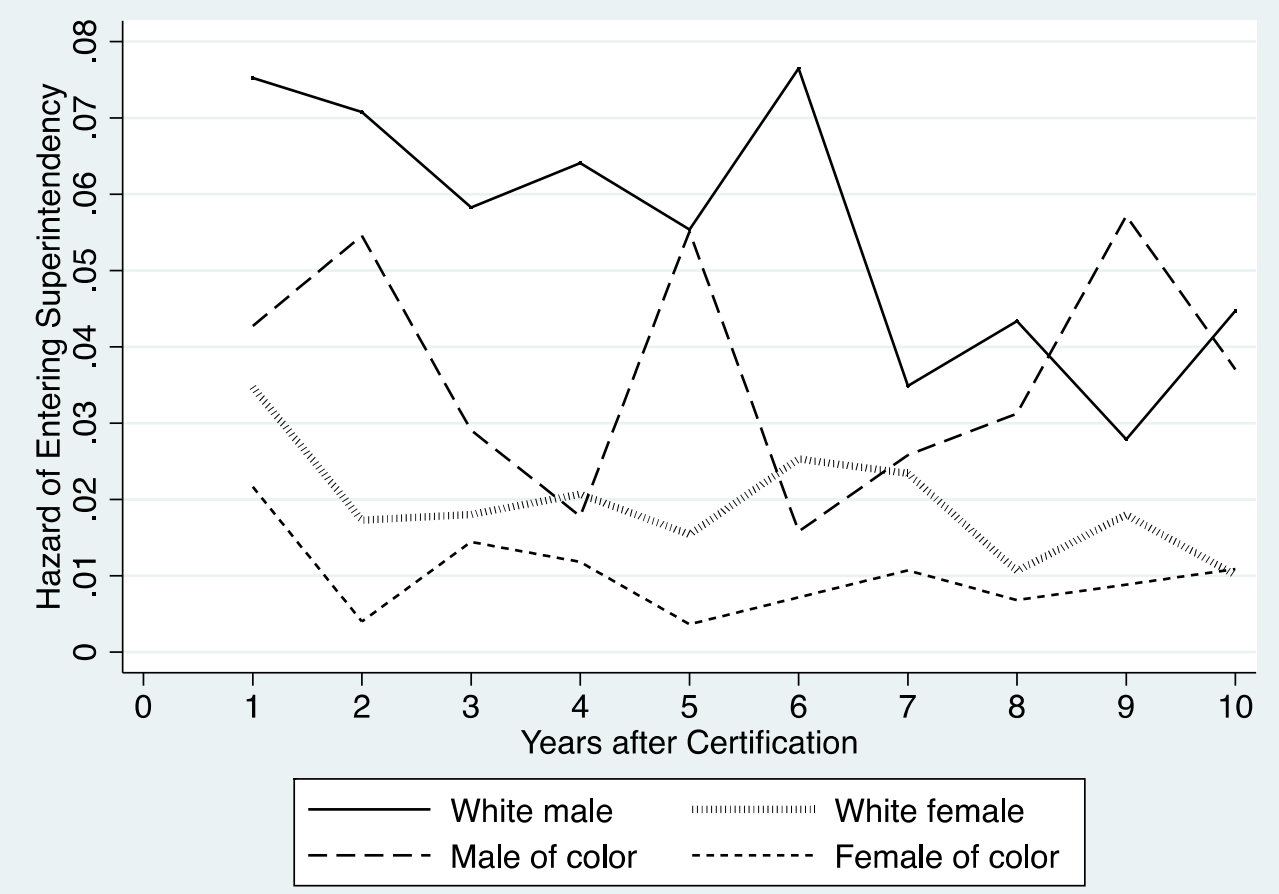


Regarding overall model fit, we followed the recommendations of the discrete-time hazard literature (Singer \& Willett, 1993, 2003; Willet \& Singer, 1995; Yamaguchi, 1991) and focus on the likelihood of our models in comparison to one that perfectly fits the data (a hypothetical situation with a unique parameter for each observation). Deviance measures allow for such a comparison, wherein a reduction suggests improved fit. In our case, a test of the reduction in deviance between a model containing only period intercepts (unconditional hazard) and model 1 (table 4) had high statistical significance ( $\mathrm{p}<.001$ ), suggesting acceptable model fit. The same was true of a test on the reduction in deviance between model 1 and model 2. With regards to parsimony, the Aikake and Bayesian Information Criteria (AIC and BIC) are alternate deviance measures that reward parsimony and penalize the addition of variables (Singer $\&$ Willett, 1993, 2003). The AIC and BIC measures reported for model 1 are substantially smaller than for the period intercepts only model, again suggesting acceptable model fit. Further, and despite the addition of the four dummy variables accounting for level of employment at time of certification, the AIC and BIC measures for model 2 represent improvement over model 1 .

Having described the fit of the DTH model, we now move to a review of specific findings, of which there are many. We begin with a discussion of time, then transition to the individual and contextual characteristics with statistical significance. The highest period-specific coefficient in both models is for period 1 , suggesting that the peak probability of superintendent certificate holders transitioning to the superintendency occurs within one year of obtaining certification, holding all other variables constant. This finding corresponds with our life table and visual displays of hazard. It also falls in line with Bjork et al. (2003) who found that participants reported first entering the superintendency 1.36 years after certification. Further support for this finding comes from Kowalski et al. (2011) who concluded that roughly two thirds of first time superintendents obtained their position within one year of beginning their searches. Our finding of early peak hazard might also be evidence that novice superintendents are "tapped" (Myung, Loeb, \& Horng, 2011) for their positions and secure certification quickly after being so. We revisit this notion in the discussion section.

Additional findings around time suggest a nonlinear relationship between age and the odds of becoming a superintendent, whereby additional years in age are helpful only up to a certain point. The same relationship exists for number of years in education. The number of years employed within a district has a negative influence on the odds of becoming a superintendent. We attribute this finding to the commonality of districts hiring outsiders to be superintendent.

In both models, the odds of doctoral degree holders becoming superintendents are greater than twice those of non-doctoral degree holders, controlling for all other variables. Further, and controlling for all other variables, coming from a district of 1,001 or more students is associated with a decrease in the odds of becoming a superintendent. The same is true for coming from a district-situated in/around a town, suburb, or city. These findings provide support to our earlier suppositions that superintendent certificate holders from small and rural districts are more likely to become superintendents than their peers from larger and more urban districts, holding all other variables constant. This seems reasonable, as lower enrollment and rural districts have a smaller central office, and therefore fewer positions within the hierarchy that are "competing" for the superintendency. None of the student demographic measures had statistical significance in either model. Additionally, both models indicate that coming from a district that met accountability standard is associated with a decrease in the odds of becoming a superintendent. We posit that this may be due to lower turnover of already sitting superintendents in districts that perform well on standardized test scores, as well as the possibility that school and central office leaders in districts that meet accountability standards may perhaps choose not to become superintendents.

The conditional, main effect of Black is negative and statistically significant in model 1 , but not in model 2 . We presume this has to do with the distribution of certificate holder race/ethnicity and sex across district typologies and levels of employment. The conditional main effect of female is negative and statistically significant in both models. The odds ratio for female in model 2 is .334, and when inverted suggests the odds of males entering the superintendency are essentially 3 times greater than that of females, controlling for all other variables in the model. In light of the conditional main effects of the race/ethnicity variables, this suggests the influence of sex on the likelihood of becoming a superintendent may be greater than that of race/ethnicity, when controlling for all other variables in the model. Further evidence for this supposition is given by the lack of statistical significance for any of the race/ethnicity and sex interaction terms. Keep in mind that due to the interaction terms, the odds ratio for female does not represent an unconditional, main effect of sex. The fact that none of the interactions of race/ethnicity with female were statistically significant in either model came as a surprise to us, particularly in light of the findings from the alluvial diagrams and survival analysis.

Finally, the dummy variables accounting for level of employment were all statistically significant in model 2. Taken together, they suggest that those employed in high school positions at the time of certification have substantially greater odds of becoming superintendents than those whom were employed in elementary, middle, or "other" campuses. The odds of entering the superintendency for those employed in central office roles were nearly double (1.875) those who obtained certification while employed in a high school role. We take up these and other findings with greater detail in the next section of the paper.

\section{DISCUSSION:}

Through this study, we have investigated career pathways into the public school superintendency with particular interest in determining how individual and contextual characteristics associate with the odds of becoming a superintendent. In terms of role at time of certification and role in the year prior to becoming a superintendent (what we term here as "stepping 
Table 4: Discrete Time Hazard Model

\begin{tabular}{|c|c|c|c|c|c|c|c|c|}
\hline & \multicolumn{4}{|c|}{ Model 1} & \multicolumn{4}{|c|}{ Model 2} \\
\hline & Coeff. & SE & Odds ratio & $\mathrm{p} \leq \mathrm{x}$ & Coeff. & SE & Odds ratio & $p \leq x$ \\
\hline \multicolumn{9}{|l|}{ Period intercepts } \\
\hline Period 1 & 0.863 & 0.112 & 2.370 & $* *$ & 0.985 & 0.117 & 2.678 & $* *$ \\
\hline Period 2 & 0.608 & 0.121 & 1.836 & $* *$ & 0.735 & 0.125 & 2.085 & $* *$ \\
\hline Period 3 & 0.391 & 0.133 & 1.479 & $* *$ & 0.548 & 0.136 & 1.731 & $* *$ \\
\hline Period 4 & 0.512 & 0.140 & 1.669 & $* *$ & 0.675 & 0.144 & 1.963 & $* *$ \\
\hline Period 5 & 0.399 & 0.153 & 1.491 & $* *$ & 0.584 & 0.157 & 1.793 & $* *$ \\
\hline Period 6 & 0.742 & 0.158 & 2.101 & $* *$ & 0.924 & 0.162 & 2.520 & $* *$ \\
\hline Period 7 & 0.258 & 0.200 & 1.294 & & 0.462 & 0.203 & 1.587 & $*$ \\
\hline Period 8 & 0.157 & 0.225 & 1.170 & & 0.397 & 0.228 & 1.487 & \\
\hline Period 9 & 0.021 & 0.264 & 1.021 & & 0.264 & 0.267 & 1.302 & \\
\hline Period 10 & 0.290 & 0.282 & 1.336 & $*$ & 0.557 & 0.283 & 1.746 & $*$ \\
\hline Period 11 & 0.182 & 0.365 & 1.199 & & 0.398 & 0.369 & 1.489 & \\
\hline Period 12 & -0.365 & 0.554 & 0.694 & & -0.098 & 0.545 & 0.906 & \\
\hline Period 13 & -0.397 & 0.740 & 0.672 & & -0.158 & 0.745 & 0.854 & \\
\hline \multicolumn{9}{|l|}{ Individual Characteristics } \\
\hline Age & 3.352 & 0.453 & 28.554 & $* *$ & 3.126 & 0.464 & 22.786 & $* *$ \\
\hline Age squared & -3.542 & 0.466 & 0.029 & $* *$ & -3.345 & 0.477 & 0.035 & $* *$ \\
\hline Doctoral degree & 0.834 & 0.109 & 2.302 & $* *$ & 0.806 & 0.110 & 2.240 & $* *$ \\
\hline Years with district & -0.239 & 0.048 & 0.788 & $* *$ & -0.268 & 0.048 & 0.765 & $* *$ \\
\hline Years in education & -0.984 & 0.123 & 0.374 & $* *$ & -0.982 & 0.125 & 0.375 & $* *$ \\
\hline Years in education squared & 1.349 & 0.142 & 3.855 & $* *$ & 1.343 & 0.144 & 3.831 & $* *$ \\
\hline Black & -0.552 & 0.279 & 0.576 & * & -0.354 & 0.279 & 0.702 & \\
\hline Latinx & -0.012 & 0.159 & 0.988 & & -0.125 & 0.160 & 0.883 & \\
\hline Other & -0.413 & 0.353 & 0.661 & & -0.381 & 0.354 & 0.683 & \\
\hline Female & -1.006 & 0.094 & 0.366 & $* *$ & -1.101 & 0.099 & 0.332 & $* *$ \\
\hline Female * Black & -0.758 & 0.594 & 0.468 & & -0.653 & 0.594 & 0.521 & \\
\hline Female * Latinx & 0.150 & 0.272 & 1.162 & & 0.163 & 0.276 & 1.177 & \\
\hline Female * Other & -0.461 & 1.092 & 0.631 & & -0.443 & 1.122 & 0.642 & \\
\hline \multicolumn{9}{|l|}{ Starting Level (ref. high school) } \\
\hline Central Office & & & & & 0.629 & 0.102 & 1.875 & $* *$ \\
\hline Elementary & & & & & -0.600 & 0.111 & 0.549 & $* *$ \\
\hline Middle & & & & & -0.729 & 0.121 & 0.482 & $* *$ \\
\hline Other & & & & & -0.893 & 0.136 & 0.409 & $* *$ \\
\hline \multicolumn{9}{|l|}{ District Controls } \\
\hline$\%$ Students econom. disadv. & -0.061 & 0.057 & 0.941 & & -0.028 & 0.058 & 0.973 & \\
\hline$\%$ Students Black & -0.038 & 0.054 & 0.962 & & -0.074 & 0.056 & 0.929 & \\
\hline$\%$ Students Latinx & 0.101 & 0.058 & 1.106 & & 0.067 & 0.059 & 1.070 & \\
\hline \multicolumn{9}{|l|}{ Enrollment (ref. 1-1000) } \\
\hline Enrollment $1,001-5,000$ & -1.579 & 0.092 & 0.206 & $* *$ & -1.769 & 0.096 & 0.170 & $* *$ \\
\hline Enrollment 5,001-25,000 & -2.325 & 0.143 & 0.098 & $* *$ & -2.584 & 0.146 & 0.075 & $* *$ \\
\hline Enrollment 25,000+ & -3.641 & 0.272 & 0.026 & $* *$ & -3.854 & 0.274 & 0.021 & $* *$ \\
\hline \multicolumn{9}{|l|}{ Urbanicity (ref. rural) } \\
\hline Town & -0.442 & 0.133 & 0.643 & $* *$ & -0.440 & 0.134 & 0.644 & $* *$ \\
\hline Suburb & -0.426 & 0.166 & 0.653 & $* *$ & -0.469 & 0.167 & 0.626 & $* *$ \\
\hline City & -0.534 & 0.193 & 0.586 & $* *$ & -0.570 & 0.195 & 0.565 & $* *$ \\
\hline Met Accountability Standard & -2.350 & 0.092 & 0.095 & $* *$ & -2.229 & 0.098 & 0.108 & $* *$ \\
\hline \multicolumn{9}{|l|}{ Goodness of fit } \\
\hline Deviance (-2 log likelihood) & 6056.21 & & & & 5877.01 & & & \\
\hline$p$ & $<0.001$ & & & & $<0.001$ & & & \\
\hline AIC & 6128.21 & & & & 5957.01 & & & \\
\hline BIC & 6422.20 & & & & 6283.67 & & & \\
\hline
\end{tabular}

Notes: $* \mathrm{p} \leq .05, * * \mathrm{p} \leq .01$ 
stones"), we revealed through alluvial diagramming that the most common pathway into the superintendency in Texas, is through the principalship. More specifically, the largest group (36.94\% of those under study) that eventually became superintendents were principals in the academic year when they first obtained superintendent certification and in the year before they first entered the superintendency. This finding was not consistent across race/ethnicity and sex, as the common most pathways for educators of color and females began and went through the assistant-superintendency. In other words, females and educators of color were more likely to have obtained superintendent certification and accepted their first superintendency position while employed as assistantsuperintendents. We attribute two potential causes for this difference. First, as noted in the literature review above through the use of gatekeeping theory, females and educators of color may have a stronger requirement to have held a district level position prior to the superintendency, while male and White educators more often move from the principalship to the superintendency (Brunner \& Grogan, 2007; Tallerico, 2000b). Second, as our descriptive analyses revealed, the race/ethnicity and sex of aspirants is not distributed evenly across either educator role or level of employment.

Through discrete-time hazard modeling, we determined that educators are most likely to enter the superintendency in the academic year immediately following that in which they obtain the requisite certification. This is the opposite from research on the principalship, which has shown that teachers do not reach their peak likelihood of becoming principals until roughly six years after gaining the required certification (Davis et al., 2017). For the most part, the likelihood of entering the superintendency continues to drop off in each year after obtaining superintendent certification. Further, we determined across both models that age, experience, education, and sex all have statistically significant impacts on the likelihood of becoming a superintendent. The conditional main effect of female indicates that female educators are far less likely than their male and nonBlack counterparts to become superintendents. The conditional main effect of Black was only significant in model 1, and suggested that Black certificate holders were less likely to become superintendents than White certificate holders. However, after adding additional controls for level of employment at time of certification, the conditional main effect of Black was no longer significant. As mentioned previously, we were surprised that none of the race/ethnicity and sex interaction terms were statistically significant in either model given the alluvial diagrams and descriptive statistics. Race/ethnicity and sex are undoubtedly associated with pathways to the superintendency as is evidenced in our alluvial diagrams and survival analysis, however that association appears to be related to the combination of individual and contextual characteristics accounted for in the discrete time hazard model, perhaps most notably, district context (enrollment and urbanicity) and level of employment.

Some of the contributions that stem from this study include a greater understanding of the stepping stones between certification and the superintendency and how those steps differ depending upon race/ethnicity and sex, as well as a clearer understanding of whether and when educators enter the superintendency and how that likelihood of transition, again, differs by race/ethnicity and sex.

Just as entering the principalship after obtaining principal certification is a relatively rare occurrence (Davis et al., 2017), there is a low incidence of superintendent certificate holders actually entering superintendency. There are a variety of potential explanations here, chief amongst which is that educators obtain these certifications for roles other than the superintendency. Unlike with the principalship, there is always only one superintendent within a given school district. Whether or not educators actually aspire to be a superintendent, it appears that most ultimately use the certification to be assistant superintendents or other district-level leadership roles.

The steep decline over time in the likelihood of superintendent certification holders entering the superintendency came as a bit of a surprise to us, particularly in light of our previous finding (Davis et al., 2017) that principal certificate holders are mostly likely to enter the principalship five to seven years after obtaining certification. We continue to be drawn to Myung, Loeb, and Horng's (2010) concept of tapping as an explanation for this. Myung et al. investigated the role that administrators encouraging teachers to become principals plays in the sustenance of the leadership pipeline. With regards to the superintendency, the tapper could be a sitting superintendent, school board member, headhunter, search committee member, etc. If it were shown that a large proportion of those who eventually became superintendents were tapped at a time they did not hold the requisite certification, that could explain the steep drop off in the odds of becoming a superintendent. In other words, many eventual superintendents might have a spot being held for them when they obtain certification. This would make sense in Texas, because superintendent certification is not required to be employed as a district-level administrator. In fact, another one of our ongoing studies suggest that a large proportion of district-level leaders (e.g. curriculum directors, assistant superintendents, etc.) have principal certification, but nothing higher (data not shown). Given that is the case, then a difference in time between certification and job procurement for principals and superintendents, should perhaps not come as a surprise at all. District level administrators necessarily have leadership experience, whereas principal certificate holders may not, and would therefore have to demonstrate readiness for the position through time spent in the assistant principalship.

\section{Implications}

School boards and the search firms they so often employ should perhaps revisit the amount and kind of experience (pathways) that matters to them, and why. Here, we are drawn back to Tallerico's (2000b) warning about the over-focus on match between applicant experience and district context, at the expense of an evaluation of leadership skills, much less recognition that such skills can be developed while employed in a variety of roles and levels. The risk of overlooking skills and overemphasizing 
match is likely because "most school board members do not scrutinize the original files of applicants" but rather "rely on the consultant's abbreviated summaries" which prioritize "prior administrative positions, name and size of district, and number of years in each position" (pp. 81-82). Are there perhaps arbitrary or antiquated understandings of the role that time and particular stepping stones play in demonstrating readiness for the superintendency?

School boards and search firms might also need greater intentionality in shaping the composition of their applicant pool as they require its individual members to pass through the various "gates" of the screening process. That is to say, they should undertake efforts to recruit and maintain a qualified and diverse talent pool of potential superintendents. This has direct ties to Cokley and Awad's (2013) insistence upon the "active use" of social justice quantitative research outcomes. Part of meeting this goal includes sharing findings with state and local education agencies to develop a base-level awareness. In an ideal world, this could lead to intentional collaboration between researchers and practitioners to establish and renew leadership pipelines that are purposed toward equity in opportunity.

Superintendent preparation programs also have a role in shaping the leadership pipeline. Not only should programs take steps to expand the diversity of their applicants, enrollees, and graduates, but they should also be up front with the realities of the position with their students about the conditions of the career pathways they will encounter upon graduation. This could lead to a new generation of district leaders that are better prepared to take an active role in ensuring more equitable opportunity for aspiring superintendents. Preparation programs must also be cognizant of the fact that the peak likelihood of their graduates becoming superintendents immediately follows program completion (ostensibly when they obtain certification). This a great responsibility for preparation programs that has implications for timing of course/program activities (e.g. resume development and interview exercises), curriculum, and professional networking (e.g. getting advanced candidates in front of prospective districts and school boards). With regards to professional networking, preparation programs could play a role in establishing and supporting peer networks or mentorships that fill the vacuum of support for female administrators of color cited by Angel et al. (2013) and Brown (2014).

Moving to implications for research, our attention to the intersectionality of race/ethnicity and sex is a practice that we encourage be continued in future studies of the superintendency. Further, we encourage further use of survival analysis as it reveals a level of information about when transitions occur, that simpler analyses cannot. Superintendent searches start and stop at curious times, as some are very short and some go on for years, therefore data that reflects with greater precision the timing of entry into the superintendency (date of hire, rather than year of role change) could be of use. We have only scratched the surface in terms of alluvial diagramming's potential to change the way that educator career pathways are presented. Further exploration of this analytical technique could produce great benefits for the field.

\section{Limitations}

Despite its tremendous diversity in terms of educator workforce, overall student body, district size, and urbanicity, Texas may not be like other states in terms of both the talent pool and schools and school district characteristics. That is to say, our findings may not necessarily be reflective of the conditions of the superintendent pipeline in other states.

We regret that some of our analysis reinforce a White/NonWhite binary that is all too common in extant educational administration research. Although the discrete time hazard modelling accounted for various intersections of race/ethnicity and sex, the alluvial diagrams did not. The primary reason for this is out of consideration for space.

Finally, our adaptation of gatekeeping theory is purposeful, yet we acknowledge that we do not consider data collected from gatekeepers themselves. Instead, we focused on the criteria shown through the literature to exert force on gatekeepers' decision-making. We have high hopes for future mixed-methods studies that can draw on qualitative traditions to garner greater insight (how and why) to the findings (what) that we have related here. Of particular interest would be mixed methods and/or qualitative studies that account for aspirant habitus and the rates at which they apply for and accept interview invitations and job offers for superintendent vacancies. Further, it would be of value to investigate differences amongst gatekeepers from various backgrounds and across varying district contexts.

\section{Conclusion}

Just as alluvial fans at the terminus of an ancient river might be made of millions of unique pathways carved out by only a few drops of water, so too are the pathways to the superintendency comprised of an untold sequences of stepping stones. To account for all of those in a single study would be overwhelming, but we view the present study as a starting point for moving forward the field's understanding of educator movement. We see similar applications in education research (e.g. tracking novice teachers, documenting mobile student populations, transfer students in higher education) and beyond (e.g. other field examples.). Further, we view this study as part of a broader project aimed at pursuing social justice in schooling, as equity in educator opportunity is part and parcel of the effort to ensure equity for students. As the availability of educational data rapidly increases, so too must our methodological approaches to analyzing it.

\section{Acknowledgement}

We are grateful to Mark A. Gooden for his thoughtfulness in providing commentary that helped to improve this manuscript.

\section{Note:}

1 - We recognize that race and ethnicity are related, but ultimately separate constructs (Bonilla-Silva, 1999; Smedley, 1998). Our use of the term race/ethnicity to describe parts of our 
study is in purposeful recognition of our reliance upon Texas Education Agency (TEA) administrative data, which contains a variable combining race and ethnicity to categorize educators. We use the term Latinx to refer to those originally labeled as Hispanic in the TEA data. Latinx is a more gender-inclusive (Johnston-Guerrero, 2016) form of Latino, a term with greater historical and geographical accuracy than Hispanic in identifying the broader community (González \& Gándara, 2005; SandrinoGlasser, 1998). Finally, and in keeping with the established norms of this and other UCEA journals, we use the term "of color" to refer to individuals that are not White. We recognize that such categorization of individuals runs the risk of reifying problematic, socially-constructed notions of difference, but it is our hope that this risk is offset by our intent to disrupt race and sex based inequities in the opportunities afforded to educators.

2 - Other superintendent assignments could have occurred during the time period observed in our study, most notably those relating to individuals whom first obtained superintendent certification before 2000-01 or whom directly entered the superintendency from an out-of-state role. Out-of-state certified educators typically earn their Texas credential by first obtaining a "one-year certificate", then using that year to complete all requirements for the "standard certificate". Only $1.3 \%$ of all superintendent certifications issued during the observation period were one-year certificates granted to educators outside of the state.

\section{Suggested Citation:}

Davis, B., Bowers, A.J. (2019) Examining the Career Pathways of Educators with Superintendent Certification. Educational

Administration Quarterly, 55(1), 3-41.

https://doi.org/10.1177/0013161X18785872

\section{References}

Alsbury, T. L. (2003). Superintendent and school board member turnover: Political versus apolitical turnover as a critical variable in the application of the dissatisfaction theory. Educational Administration Quarterly, 39(5), 667-698. https://doi.org/10.1177/0013161X03257141

Alsbury, T. L. (2008). School board member and superintendent turnover and the influence on student achievement: An application of the dissatisfaction theory. Leadership and Policy in Schools, 7(2), 202-229. https://doi.org/10.1080/15700760701748428

Angel, R. B., Killacky, J., \& Johnson, P. R. (2013). African American women aspiring to the superintendency: Lived experiences and barriers. Journal of School Leadership, 23(4), 592-614.

Björk, L., Keedy, J., \& Gurley, D. K. (2003). Career patterns of American superintendents. Journal of School Leadership, 13(4), 406-427.

Bonilla-Silva, E. (1999). The essential social fact of race. American Sociological Review, 64(6), 899-906.

Bowers, A. J. (2010). Grades and graduation: A longitudinal risk perspective to identify student dropouts. The Journal of Educational Research, 103(3), 191-207. https://doi.org/10.1080/00220670903382970
Brown, A. R. (2014). The recruitment and retention of African American women as public school superintendents. Journal of Black Studies, 45(6), 573-593. https://doi.org/10.1177/0021934714542157

Brunner, C. C. (2008). Invisible, limited, and emerging discourse: Research practices that restrict and/or increase access for women and persons of color to the superintendency. Journal of School Leadership, 18(6), 661.

Brunner, C. C., \& Grogan, M. (2007). Women leading school systems: Uncommon roads to fulfillment. Lanham, Md: Rowman \& Littlefield Education: In partnership with the American Association of School Administrators.

Cokley, K. O., \& Awad, G. H. (2013). In defense of quantitative methods: Using the "master's tools" to promote social justice. Journal for Social Action in Counseling and Psychology, 5(2), 26-41.

Cooper, B. S., Fusarelli, L. D., Jackson, B. L., \& Poster, J. (2002). Is "superintendent preparation" an oxymoron? Snalyzing changes in programs, certification, and control. leadership and policy in schools, 1(3), 242-255. doi: 10.1076/lpos.1.3.242.7888

Crawford, E. R., \& Fuller, E. J. (2015). A dream attained or deferred? Examination of production and placement of Latino administrators. Urban Education, 42085915602537. https://doi.org/10.1177/0042085915602537

Dana, J. A., \& Bourisaw, D. (2006). Women in the superintendency: Discarded leadership. Rowman \& Littlefield Education.

Davis, B. W., Gooden, M. A., \& Bowers, A. J. (2017). Pathways to the principalship: An event history analysis of the careers of teachers with principal certification. American Educational Research Journal, 54(2), 207-240. https://doi.org/10.3102/0002831216687530

Fuller, E. J., Hollingworth, L., \& An, B. P. (2016). The impact of personal and program characteristics on the placement of school leadership preparation program graduates in school leader positions. Educational Administration Quarterly, $0013161 X 16656039$. https://doi.org/10.1177/0013161X16656039

Gates, S. M., Guarino, C. M., Santibanez, L., Ghosh-Dastidar, B., Brown, A. B., \& Chung, C. H. (2004). Career paths of school administrators in North Carolina. Rand.

Gates, S. M., Ringel, J. S., Santibañez, L., Guarino, C., GhoshDastidar, B., \& Brown, A. (2006). Mobility and turnover among school principals. Economics of Education Review, 25(3), 289-302. https://doi.org/10.1016/j.econedurev.2005.01.008

González, C., \& Gándara, P. (2005). Why we like to call ourselves Latinas. Journal of Hispanic Higher Education, 4(4), 392-398. https://doi.org/10.1177/1538192705279407

Grissom, J. A., \& Andersen, S. (2012). Why superintendents turn over. American Educational Research Journal, 49(6), 11461180. https://doi.org/10.3102/0002831212462622

Grissom, J. A., \& Mitani, H. (2016). Salary, performance, and superintendent turnover. Educational Administration Quarterly, $0013161 X 15627677$ https://doi.org/10.1177/0013161X15627677 
Harris, L. C., \& Ogbonna, E. (2016). Ethnic gatekeeping on the shopfloor: A study of bases, motives and approaches. Work, Employment and Society, 30(1), 59-76. https://doi.org/10.1177/0950017015606338

Horsford, S. D. (2009). From Negro student to Black superintendent: Counternarratives on segregation and desegregation. The Journal of Negro Education, 78(2), 172187.

Horsford, S. D. (2010). Mixed feelings about mixed schools: Superintendents on the complex legacy of school desegregation. Educational Administration Quarterly, 46(3), 287-321. https://doi.org/10.1177/0013161X10365825

Jackson, J., \& Shakeshaft, C. (April, 2003). The pool of African American candidates for the superintendency. A paper presented at the annual meeting of the American Educational Research Association, Chicago, IL.

Johnston-Guerrero, M. P. (2016). The meanings of race matter: College students learning about race in a not-so-postracial era. American Educational Research Journal, 53(4), 819849. https://doi.org/10.3102/0002831216651144

Kalbus, J. C. (2000). Path to the superintendency. Urban Education, 35(5), 549-556. https://doi.org/10.1177/0042085900355005

Kim, Y., \& Brunner, C. C. (2009). School administrators' career mobility to the superintendency: Gender differences in career development. Journal of Educational Administration, 47(1), 75-107. https://doi.org/10.1108/09578230910928098

Kowalski, T. J., \& Brunner, C. C. (2011). The school superintendent: Roles, challenges, and issues. Sage Handbook of Educational Leadership: Advances in Theory, Research, and Practice. Retrieved from https://works.bepress.com/theodore_kowalski/38/

Lewin, K. (1947). Frontiers in group dynamics: II. Channels of group life; Social planning and action research. Human Relations, 1(2), 143-153.

Melia, M. (2016, October 31). Quitting school: Turnover rises for urban superintendents, The Washington Post. Retrieved from https://www.washingtonpost.com/business/quittingschool-turnover-rises-for-urbansuperintendents/2016/10/31/7e5177a2-9f7f-11e6-88646f892cad0865 story.html

Muñoz, A. J., Pankake, A., Ramalho, E. M., Mills, S., \& Simonsson, M. (2014). A study of female central office administrators and their aspirations to the superintendency. Educational Management Administration \& Leadership, 42(5), 764-784. https://doi.org/10.1177/1741143213510508

Muñoz, A. J., Mills, S. J., Pankake, A., \& Whaley, S. (2014). Disparity In the superintendency. Contemporary Issues in Education Research, 7(4), 269.

Myung, J., Loeb, S., \& Horng, E. (2011). Tapping the principal pipeline identifying talent for future School leadership in the absence of formal succession management programs. Educational Administration Quarterly, 47(5), 695-727. https://doi.org/10.1177/0013161X11406112

Natkin, G. L., Cooper, B. S., Alborano, J. A., Padilla, A., \& Ghosh, S. K. (2003). Predicting and modeling superintendent turnover. Journal of School Leadership, 13(3), 328-346.

O'Brien, R. M. (2007). A caution regarding rules of thumb for variance inflation factors. Quality \& Quantity, 41(5), 673690. https://doi.org/10.1007/s11135-006-9018-6

Orr, M. T. (2006). Learning the superintendency: socialization, negotiation, and determination. Teachers College Record, 108(7), 1362-1403.

Petersen, G. J., Fusarelli, L. D., \& Kowalski, T. J. (2008). Novice superintendent perceptions of preparation adequacy and problems of practice. Journal of Research on Leadership Education, 3(2), 1-22. https://doi.org/10.1177/194277510800300204

Roberts, K., Hanna, S. L., \& Womack, S. T. (2012). The firstyear experiences of successful superintendents. $\mathrm{R} \& \mathrm{~L}$ Education.

Rosvall, M., \& Bergstrom, C. T. (2010). Mapping change in large networks. PloS One, 5(1), e8694.

Sandrino-Glasser, G. (1998). Los confundidos: De-conflating Latinos/as' race and ethnicity. Chicano-Latino Law Review, 19, 69.

SERVE. (1994). Overcoming barriers to school reform in the southeast.

Shoemaker, P. J., \& Vos, T. P. (2009). Gatekeeping theory. New York: Routledge.

Singer, J. D., \& Willett, J. B. (1993). It's about time: Using discrete-time survival analysis to study duration and the timing of events. Journal of Educational and Behavioral Statistics, 18(2), 155-195. https://doi.org/10.3102/10769986018002155

Singer, J. D., \& Willett, J. B. (2003). Applied longitudinal data analysis: Modeling change and event occurrence (1st ed.). Oxford University Press, USA.

Smedley, A. (1998). "Race" and the construction of human identity. American Anthropologist, 100(3), 690-702.

Smith, B. (2008). Deregulation and the new leader agenda: Outcomes and lessons from Michigan. Educational Administration Quarterly, 44(1), 30-65. https://doi.org/10.1177/0013161X07306454

Sperandio, J., \& Devdas, L. (2015). Staying close to home: Women's life-choices and the superintendency. Journal of Educational Administration, 53(3), 335-353. https://doi.org/10.1108/JEA-08-2013-0088

StataCorp. (2013). Stata: Release 13. College Station, TX: StataCorp, LP.

Willett, J. B., \& Singer, J. D. (1995). It's déjà vu all over again: Using multiple-spell discrete-time survival analysis. Journal of Educational and Behavioral Statistics, 20(1), 41-67.

Tallerico, M. (2000a). Gaining access to the superintendency: Headhunting, gender, and color. Educational Administration Quarterly, 36(1), 18-43. https://doi.org/10.1177/00131610021968886

Tallerico, M. (2000b). Accessing the superintendency: The unwritten rules. Thousand Oaks, CA: Corwin Press.

Yamaguchi, K. (1991). Event history analysis. Newbury Park, CA: Sage Publications 